\title{
Evidence-based practice in mental health
}

Welcome to the first issue of Evidence-Based Mental Health, a journal designed to help mental health clinicians stay up to date with the best available evidence as it is published. Evidence-Based Mental Health is one of a number of resources being developed to help clinicians who want to use the strategies of evidence-based practice (EBP). ${ }^{1} \mathrm{EBP}$ harnesses recent advances in clinical epidemiology, biostatistics, and information science to produce a coherent and comprehensive approach to allow clinicians to base their practice on the best available evidence.

EBP, far from being an esoteric activity pursued by ivory tower academics with too much time on their hands, meets a real clinical need. Evidence suggests that clinicians tend to underestimate their information requirements and, when they do recognise a need for information, they do not access the most reliable and least biased sources. ${ }^{2}$ This leads to a gap between research and clinical practice which manifests as unwarranted variations in clinical practice. There are only 2 explanations for these variations: either there is no evidence on which to base practice, or that there is evidence, but at least some of us are not using it. ${ }^{3}$ The inevitable result of these variations is that some patients are not receiving the best available care.

There are several examples of the existence of such variations. One of the clearest findings in the field of mental health is the under recognition and diversity in the treatment of depression in various healthcare settings. It has proved difficult to narrow this gap between research and practice despite the production of increasingly emphatic consensus statements. ${ }^{4}$ Within specialist psychiatric practice, there are the unexplained variations in the rates of use of electroconvulsive treatment both in the United States and the United Kingdom. ${ }^{67}$ There are also variations in the rates of prescription of stimulants in attention deficit hyperactivity syndrome, which have been attributed, at least in part, to a preference for opinion over evidence ${ }^{8-10}$ Clinical practice in psychology and mental health nursing has not been studied as closely. However, in clinical psychology, Wilson has asserted that "in clinical practice empirically-supported methods are routinely ignored in favour of intuition and clinical experience". ${ }^{11}$ In nursing, although there has been an increase in published research, it seems that few of these findings are used in clinical practice. ${ }^{12}{ }^{13}$ Overall, the field has also been particularly susceptible to the influences of fashion and ideology. There is evidence that there is still a split among biological and psychotherapeutic psychiatrists ${ }^{14}$-not to mention the split among the beliefs of different professional groups. Furthermore, many research findings conflict with commonly held public assumptions about mental health. ${ }^{15}$

Of course, not all variations in clinical practice represent such an "evidence gap". Some variations are justified; they represent the influences of clinical expertise, patient preference, or an absence of good quality evidence. EBP does not suggest that clinical practice should become tyrannised by the evidence. EBP should help busy clinicians keep up to date and meet the objective of ensuring that clinical practice is based on the best available evidence, integrated with clinical expertise and patient preference, and leading to the best possible patient care.

It should also be emphasised that the aims of EBP are not particularly new-a strong history exists of implementing research findings in clinical practice in the field of mental health. One of the most striking examples is the development of explicit diagnostic criteria such as the American Psychiatric Association's Diagnostic and Statistical Manual, 3rd edition which was in response to variations in diagnostic practice. ${ }^{16}$

There are a number of ways of trying to narrow the gap between research and practice. The methodology of reviewing and summarising evidence has developed dramatically over the past decade with the production of evidence-based clinical practice guidelines and the preparation and maintenance of high quality overviews, such as those in the Cochrane Library. ${ }^{17}$ These initiatives may fail to influence practice, however, if they are not implemented effectively. Commonly used approaches to increase the implementation of research findings in clinical practice include the growing requirement for continuing professional development (CPD). Many of the methods used in CPD, however, are of limited effectiveness. ${ }^{18} \mathrm{EBP}$ uses the most effective strategies known for changing professional practice. It enables clinicians to become self directed, problem based, adult learners who can recognise gaps in knowledge; pose well formulated, answerable, clinical questions; locate the best available evidence; critically appraise it; and integrate the results with their clinical expertise. ${ }^{19}$

One of the key elements in making EBP a feasible proposition for busy clinicians is the requirement for rapid access to high quality evidence. Keeping up to date is a particular problem in mental health because of the multidisciplinary nature of the subject. Each profession has its own journal or journals and our reading of other relevant literature may be restricted by lack of access to, or even antipathy towards, certain research findings due to our adherence to a particular school of thought.

The aim of Evidence-Based Mental Health is to help the mental health clinician keep up to date with the best, clinically relevant research in the field. The journal will use a similar approach to that applied successfully by the ACP Journal Club and Evidence-Based Medicine. (see purpose and procedure $\mathrm{p}$ 2-3). It will cut across professional boundariesthe aim is to abstract the best research wherever it is published and whomever it is done by. A fundamental principle of EBP is that specific study designs are best able to provide unbiased answers for different kinds of clinical questions. Thus, for a question concerning treatment, good quality randomised trials (either single trials or meta-analyses of several comparable trials) produce the most valid estimates of a treatment's effectiveness. For a question concerning 
diagnosis, a cross sectional study of subjects suspected of having the disorder, in which the diagnostic test is given masked to the true disease status of the patient according to the best available diagnostic standard, provides the best estimate of the usefulness of the test. For prognosis, an inception cohort, which is an unselected sample of patients assembled at a uniform point in the development of the disease (especially first onset), gives the most valid and useful results. In Evidence-Based Mental Health, we select only studies whose methodology meets explicit, stringent, and empirically defined criteria and whose results are likely to be both true and clinically important (see purpose and procedure p 2-3).

The editors of the journal are a general adult psychiatrist (JG), a clinical psychologist who is responsible for a training course (SR), a clinical psychologist who is also an epidemiologist and biostatistician (DS), and a child psychiatrist (PS). The coordinating editor ( $\mathrm{BH})$ is also editor of Evidence-Based Medicine and ACP Journal Club and is chief of the Health Information Research Unit at McMaster University which hosts the editorial office for the journals. We intend to recruit associate editors with specialist clinical expertise to ensure that the journal is selecting the most relevant research. We are also in the process of recruiting experts who are willing to prepare commentaries (and cope with the exacting deadlines of the production team!) and also to provide advice on the abstracts which are prepared by the research associates in the Health Information Research Unit at McMaster University.

We hope that Evidence-Based Mental Health will function as a forum for the development of EBP in mental health. In particular, some clinical questions may require different research designs than those which are currently considered for abstraction in the journal. For example, it is often useful to have an estimate of the prevalence or likelihood of the condition in a specific setting because this helps the clinician consider likely problems or diagnoses. Similarly, in mental health, patients often value a clinician who can empathise and understand their problem, and qualitative studies often provide useful information about the experience of mental illness which can assist in the clinician's attempts to understand a particular patient's experiences. Initially, we will not include prevalence or qualitative studies because we still need to develop and test suitable methodological criteria for detecting when such articles are likely to be valid and useful from the primary journals. These criteria are currently being developed; we will begin with prevalence studies and then move on to qualitative studies. Within psychotherapy research there is also much interest in the process of treatment and we plan to develop criteria for selecting clinically useful articles on this subject.

Evidence-Based Mental Health will be included in the annually updated CD Best Evidence published by the American College of Physicians. Best Evidence also contains the accumulated abstracts from ACP Journal Club since 1991 and Evidence-Based Medicine since 1995 and thus is already a robust compendium of continually updated, critically appraised, and summarised evidence. Finally, Evidence-Based Mental Health will be featured on the BMJ Publishing Group World Wide Web site, http://www.evidbasedmentalhealth.com and there will be a launch conference in London on the 16th February 1998. We invite you to join us in our efforts to make it easier for mental health professionals to get access to the best evidence. Firstly, please subscribe to the journal, if you have not already! Secondly, we would be grateful if you could complete and return to us the commentator form that is inserted in this first issue of the journal. We look forward to hearing your views on what we are, or should be, doing to improve the link between sound evidence from research and the care that we offer our patients.

JOHN GEDDES, MD

SHIRLEY REYNOLDS, MSc

DAVID STREINER, PhD

PETER SZATMARI, MD BRIAN HAYNES, MD, PhD

1 Haynes RB, Sackett DL, Gray JRA, et al. Transferring evidence from research into practice: getting the evidence straight [editorial]. ACP JC 1997 Jan-Feb;126:A14-6.

2 Smith R. What clinical information do doctors need? BMJ 1996;313:1062-

3 Kendell RE. The College and "clinical effectiveness". Psychiatric Bulletin 1997;21:385-6.

4 Paykel ES, Priest RG. Recognition and management of depression in general practice: consensus statement. BMJ 1992;305:1198-1202.

5 Hirschfeld RM, Keller MB, Panico S, et al. The National Depressive and Manic-Depressive Association consensus statement on the undertreatment of depression. JAMA 1997;277:333-40.

6 Pippard J. Audit of electroconvulsive treatment in two national health service regions. Br J Psychiatry 1992:160:621-37.

7 Hermann RC, Dorwart RA, Hoover CW, et al. Variation in ECT use in the United States. Am J Psychiatry 1995;152:869-75.

8 Valentine J, Zubrick S, Sly P. National trends in the use of stimulant Valentine J, Zubrick S, Sly P. National trends in the use of stimulant
medication for attention deficit hyperactivity disorder. J Paediatr Chid Health 1996;32:233-7.

9 Rappley MD, Gardiner JC, Jetton JR, et al. The use of methylphenidate in Michigan. Arch Pediatr Adolesc Med 1995;149:675-9.

10 Levy F. Attention deficit hyperactivity disorder. BMJ 1997;315:894-5.

11 Wilson GT. Treatment manuals in clinical practice. Behav Res Ther 1997;35:205-10.

12 Yonge O, Austin W, Zgou Qiuping P, et al. A systematic review of the psychiatric/mental health nursing research literature 1982-1992. Journal of Psychiatric and Mental Health Nursing 1997;4:171-7.

13 McKenna HP. Dissemination and application of mental health nursing research. British Journal of Nursing 1995;4:1257-63.

14 Bodkin JA, Klitzman RL, Pope HG Jr. Treatment orientation and associated characteristics of North American academic psychiatrists. $J$ Nerv Ment Dis 1995;183:729-35.

15 Priest RG, Vize C, Roberts A, et al. Lay people's attitudes to treatment of depression: results of opinion poll for defeat depression campaign just before its launch BMJ 1996;313:858-9.

16 American Psychiatric Association. Diagnostic and statistical manual of mental disorders (third edition DSM-III). Washington: APA, 1980

17 Mulrow CD. Rationale for systematic reviews. BMJ 1994;309:597-9.

18 Davis DA, Thomson MA, Oxman AD, et al. Changing physician performance. A systematic review of the effect of continuing medical education strategies. JAMA 1995;274:700-5.

19 Sackett DL, Richardson S, Rosenberg W, et al. Evidence-based medicine. How to practise and teach EBM. London: Churchill-Livingstone, 1997. 